Article

\title{
Hydrothermal Growth of Vertically Aligned ZnO Nanorods Using a Biocomposite Seed Layer of ZnO Nanoparticles
}

\author{
Zafar Hussain Ibupoto ${ }^{1}{ }^{*}$, Kimleang Khun ${ }^{1}$, Martin Eriksson ${ }^{2}$, Mohammad AISalhi ${ }^{4}$, \\ Muhammad Atif ${ }^{3}$, Anees Ansari ${ }^{5}$ and Magnus Willander ${ }^{1,3}$
}

1 Physical Electronics and Nanotechnology Division, Department of Science and Technology, Campus Norrköping, Linköping University, SE-60174 Norrköping, Sweden;

E-Mails: kimleang.khun@liu.se (K.K.); magnus.willander@liu.se (M.W.)

2 Department of Physics, Chemistry, and Biology (IFM), Linköping University, 58183 Linköping, Sweden; E-Mail: marer@ifm.liu.se

3 Physics and Astronomy Department, College of Science, King Saud University, 11451 Riyadh, Saudi Arabia; E-Mail: atifhull@gmail.com

4 Research Chair for Laser Diagnosis of Cancer, King Saud University, 11451 Riyadh, Saudi Arabia; E-Mail: malsalhi@ksu.edu.sa

5 King Abdullah Institute for Nanotechnology, King Saud University, 11451 Riyadh, Saudi Arabia; E-Mail: aneesaansari@gmail.com

* Author to whom correspondence should be addressed; E-Mail: zafar.hussain.ibupoto@liu.se; Tel.: +46-011-363-119; Fax: +46-011-363-270.

Received: 22 July 2013; in revised form: 24 July 2013 / Accepted: 8 August 2013 / Published: 19 August 2013

\begin{abstract}
Well aligned $\mathrm{ZnO}$ nanorods have been prepared by a low temperature aqueous chemical growth method, using a biocomposite seed layer of $\mathrm{ZnO}$ nanoparticles prepared in starch and cellulose bio polymers. The effect of different concentrations of biocomposite seed layer on the alignment of $\mathrm{ZnO}$ nanorods has been investigated. $\mathrm{ZnO}$ nanorods grown on a gold-coated glass substrate have been characterized by X-ray diffraction (XRD) and field emission scanning electron microscopy (FESEM) techniques. These techniques have shown that the $\mathrm{ZnO}$ nanorods are well aligned and perpendicular to the substrate, and grown with a high density and uniformity on the substrate. Moreover, $\mathrm{ZnO}$ nanorods can be grown with an orientation along the $c$-axis of the substrate and exhibit a wurtzite crystal structure with a dominant (002) peak in an XRD spectrum and possessed a high crystal quality. A photoluminescence (PL) spectroscopy study of the $\mathrm{ZnO}$ nanorods has revealed a conventional near band edge ultraviolet emission, along with emission in the visible part of
\end{abstract}


the electromagnetic spectrum due to defect emission. This study provides an alternative method for the fabrication of well aligned $\mathrm{ZnO}$ nanorods. This method can be helpful in improving the performance of devices where alignment plays a significant role.

Keywords: biocomposite seed layer; $\mathrm{ZnO}$ nanorods; hydrothermal growth method; starch; cellulose

\section{Introduction}

During the last two decades, a great deal of research has been performed on the synthesis of different nanostructures, which helps in the understanding of the mesophysics phenomena of growing nonmaterial. Several nanostructures of different metal oxide semiconductors with potential applications have been explored. Among these, $\mathrm{ZnO}$ is considered to be a promising material for the nanoscale based device applications due to its wurtzite crystal structure, wide direct band gap of $3.37 \mathrm{eV}$ and high exciton binding energy of $60 \mathrm{meV}$. $\mathrm{ZnO}$ nanostructures can be used in the development of light emitting diodes (LEDs) [1], piezoelectric transducers [2,3], gas sensors [4,5], dye-sensitized solar cells [6], and in medical applications [7]. As research on the fabrication and applications of $\mathrm{ZnO}$ is maturing, the pronounced effect of the morphology of $\mathrm{ZnO}$ nanostructures has been debated. It is crucial to have a controlled morphology of the nanostructures for the desired application, due to its backbone role in the performance of the device. Several methods have been reported for the synthesis of various $\mathrm{ZnO}$ nanostructures, both with physical and chemical approaches. Yet, more work is required in the synthesis of well align $\mathrm{ZnO}$ nanostructures. The oriented $\mathrm{ZnO}$ morphology is highly demanded for the construction of devices. Among the diverse morphologies of $\mathrm{ZnO}$, nanorods have gained particular attention in the research community. As a result, several approaches exist for their fabrication. To grow one dimensional $\mathrm{ZnO}$ nanostructures, such as nanorods, many expensive growth techniques are available, including pulsed laser deposition (PLD) [8], thermal evaporation [9], vapor transport deposition (VTD) [10], molecular beam epitaxy (MBE) [11], different chemical vapor deposition (CVD) techniques [12-14], and magnetron sputtering (MS) [15]. These methods require extremely severe growth conditions, including high temperature and pressure, and dangerous chemicals. Besides these, low cost and simple growth techniques, such as electrodeposition [16] and hydrothermal growth methods [17], can be used for the fabrication of one dimensional $\mathrm{ZnO}$ nanostructures. The seed-free growth of highly ordered $\mathrm{ZnO}$ nanorods is very difficult on many substrates, because of lattice mismatch. A seed layer is therefore essential in order to achieve well aligned nanorods on the substrate. Recently, several seed coating techniques have been used for the growth of well-ordered $\mathrm{ZnO}$ nanorods, such as atomic layer deposition (ALD), pulsed laser deposition (PLD) [18], electron beam evaporation (EBE) [19], the successive ionic layer adsorption and reaction (SILAR) method [20], spray pyrolysis [21], and RF sputtering techniques [22,23]. The growth of $\mathrm{ZnO}$ nanorods, homogeneously perpendicular to the substrate, is a challenging task using a simple and low temperature aqueous chemical growth method. Moreover, template assisted methods have also been used for their potential capability in the development of ordered materials in a controlled way [24,25]. 
The template assisted materials include micelles [26], membranes [27], biopolymers [28,29], as well as animal and plant tissues [30,31].

In this work, freshly prepared $\mathrm{ZnO}$ nanoparticles were homogenized with two renowned biopolymers; starch and cellulose. The biopolymer solutions were used as a seed layer for the synthesis of highly ordered $\mathrm{ZnO}$ nanorods on the gold coated glass substrates. Both starch and cellulose are among the most abundant naturally occurring biopolymers, and starch has the ability to form a variety of complexes with other molecules [32]. Starch is a polymer formed by repeating units of amylose and amylopectin through 1, 4 glycoside linkages between D-glucose units. Starch is not easily soluble in water at room temperature, but by heating the water, it forms a gelatin liquid. In this gelatin liquid, $\mathrm{ZnO}$ nanoparticles provide a large number of nucleation sites for the growth of well aligned $\mathrm{ZnO}$ nanorods. Similarly, cellulose is also a member of the starch family, and being hydrophilic in nature, it provides a useful platform for distributing $\mathrm{ZnO}$ nanoparticles on the substrate and thereby acting as an efficient seed material together with $\mathrm{ZnO}$ nanoparticles for the fabrication of well aligned $\mathrm{ZnO}$ nanorods. In addition to this, the effect of different concentrations of $\mathrm{ZnO}$ nanoparticles diffused in starch and cellulose biopolymers on the alignment of $\mathrm{ZnO}$ nanorods have been investigated.

\section{Results and Discussion}

$\mathrm{ZnO}$ nanoparticles were characterized X-ray diffraction (XRD) technique and the diffraction pattern is shown in Figure 1a. The measured diffraction peaks include 100, 002, 101, 102, 110, 103, 200, 112, and 201, which are according to the reported work [33]. The $\mathrm{ZnO}$ nanoparticles exhibited the nanocrystalline phase and no other impurity such as $\mathrm{Zn}(\mathrm{OH})_{2}$ was observed. Figure $1 \mathrm{~b}$ shows the AFM image of the biocomposite seed layer of the $\mathrm{ZnO}$ nanoparticles and it can be seen that the nanoparticles are uniform, dense and well adhered to the gold-coated glass substrate which behaved better nucleation centers for the growth of well aligned $\mathrm{ZnO}$ nanorods.

Figure 1. (a) The $\mathrm{XRD}$ pattern of $\mathrm{ZnO}$ nanoparticles; (b) The AFM image of the biocomposite seed layer of $\mathrm{ZnO}$ nanoparticles.

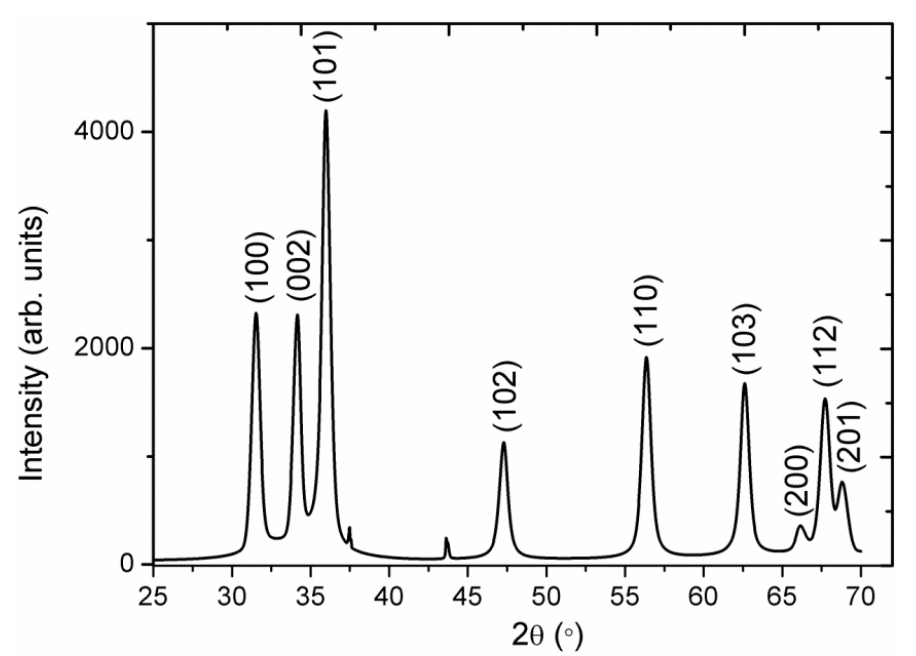

(a)

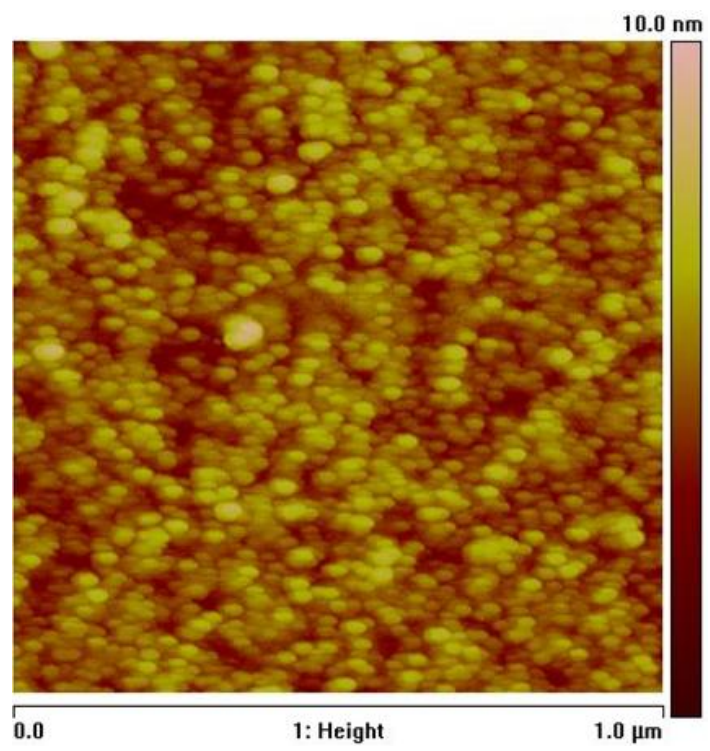

(b) 
Figure 2 shows the $\mathrm{XRD}$ spectra of as synthesized $\mathrm{ZnO}$ nanorods without the seed layer of $\mathrm{ZnO}$ nanoparticles and it can be observed that the appeared peaks are less intense especially (002) peak which proved that without seed layer the orientation of nanorods is subject of matter. However, with the seed layer consisting of $\mathrm{ZnO}$ nanoparticles in starch biocomposite as shown in Figure 3a-e, the measured diffraction peaks are almost similar, but the orientation is a bit improved. For cellulose biocomposite based seed layer, on gold-coated substrates, the observed $2 \theta$ peaks at $31.7^{\circ}, 34.4^{\circ}, 36.3^{\circ}$, $47.5^{\circ}, 56.6^{\circ}, 62.8^{\circ}, 67.9^{\circ}$, and $72.5^{\circ}$ are shown in Figure $4 \mathrm{a}-\mathrm{c}$. All the obtained XRD diffraction patterns are according to JCPDS card number 80-0075. The peaks in the XRD spectrum could be assigned to the (100), (002), (101), (102), (110), (103), (112), and (004) crystal planes of $\mathrm{ZnO}$ nanorods with wurtzite crystal structures. The nanorods grown on a starch seed layer, and in particular those grown on a cellulose seed layer, are well-ordered due to very intense peak of (002) crystal plane which shows that the growth pattern is along the $c$-axis direction as shown in Figure 4c.

A distinctive FESEM image of $\mathrm{ZnO}$ nanorods grown with the seed layer of $\mathrm{ZnO}$ nanoparticles (without starch and cellulose) is shown in Figure 5 and it can be seen that to some extent the nanorods are aligned and exhibited uniform diameter which could be due to the improper nucleation on the substrate provided by $\mathrm{ZnO}$ nanoparticles and possible the aggregation of nanoparticles. Typical FESEM images of the $\mathrm{ZnO}$ nanorods growth on seed layers of $\mathrm{ZnO}$ nanoparticles biocomposite with starch and cellulose on the gold-coated glass substrates are shown in Figures 6 and 7 respectively.

Figure 2. The XRD pattern of $\mathrm{ZnO}$ nanorods without seed solution.

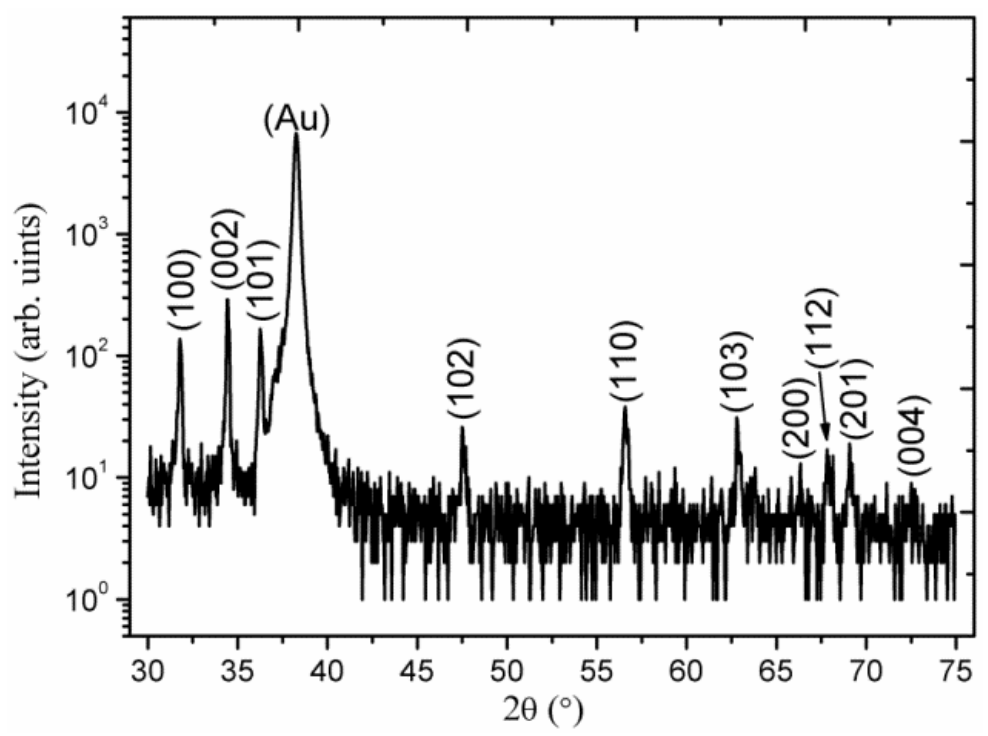

Figure 6a-g shows the $\mathrm{ZnO}$ nanorods grown with seed layer of $\mathrm{ZnO}$ nanoparticles and starch biopolymer, Figure 6a is an image of $\mathrm{ZnO}$ nanorods grown in a starch biopolymer without $\mathrm{ZnO}$ nanoparticles. It can be seen that the $\mathrm{ZnO}$ nanorods are not well ordered and the yield of nanorods on the substrate is very much less. However, with the addition of $0.5 \mathrm{mg} / \mathrm{mL}$ of $\mathrm{ZnO}$ nanoparticles in the starch solution, the grown nanorods are well aligned along the $c$-axis direction of the substrate as shown in Figure 6b. Further increasing the concentration of $\mathrm{ZnO}$ nanoparticles to 1.0, 1.5, and $2.0 \mathrm{mg} / \mathrm{mL}$ in the seed solution which resulted well-ordered $\mathrm{ZnO}$ nanorods, as shown in Figure 6c-e. This behavior can be explained by the gelatin like property of starch and the uniform distribution of 
$\mathrm{ZnO}$ nanoparticles on the surface of the starch biopolymer, which provides the possible nucleation for the growth of $\mathrm{ZnO}$ nanorods. However, by further increasing the concentration of $\mathrm{ZnO}$ nanoparticles to $2.5 \mathrm{mg} / \mathrm{mL}$ in the starch solution, the nanoparticles might start to aggregate on the surface of the starch biopolymer. The aggregation of $\mathrm{ZnO}$ nanoparticles in starch results in a loss of uniformity of the distribution of the $\mathrm{ZnO}$ nanorods, as well as a random alignment of the nanorods, as shown in Figure $6 \mathrm{f}$.

Figure 3. The $\mathrm{XRD}$ pattern of $\mathrm{ZnO}$ nanorods growth with seed solutions containing $3.5 \mathrm{mg} / \mathrm{mL}$ of starch concentration and different concentrations of $\mathrm{ZnO}$ nanoparticles: (a) 0.5 ; (b) 1.0 ; (c) 1.5 ; (d) 2.0 ; and (e) $2.5 \mathrm{mg} / \mathrm{mL}$.
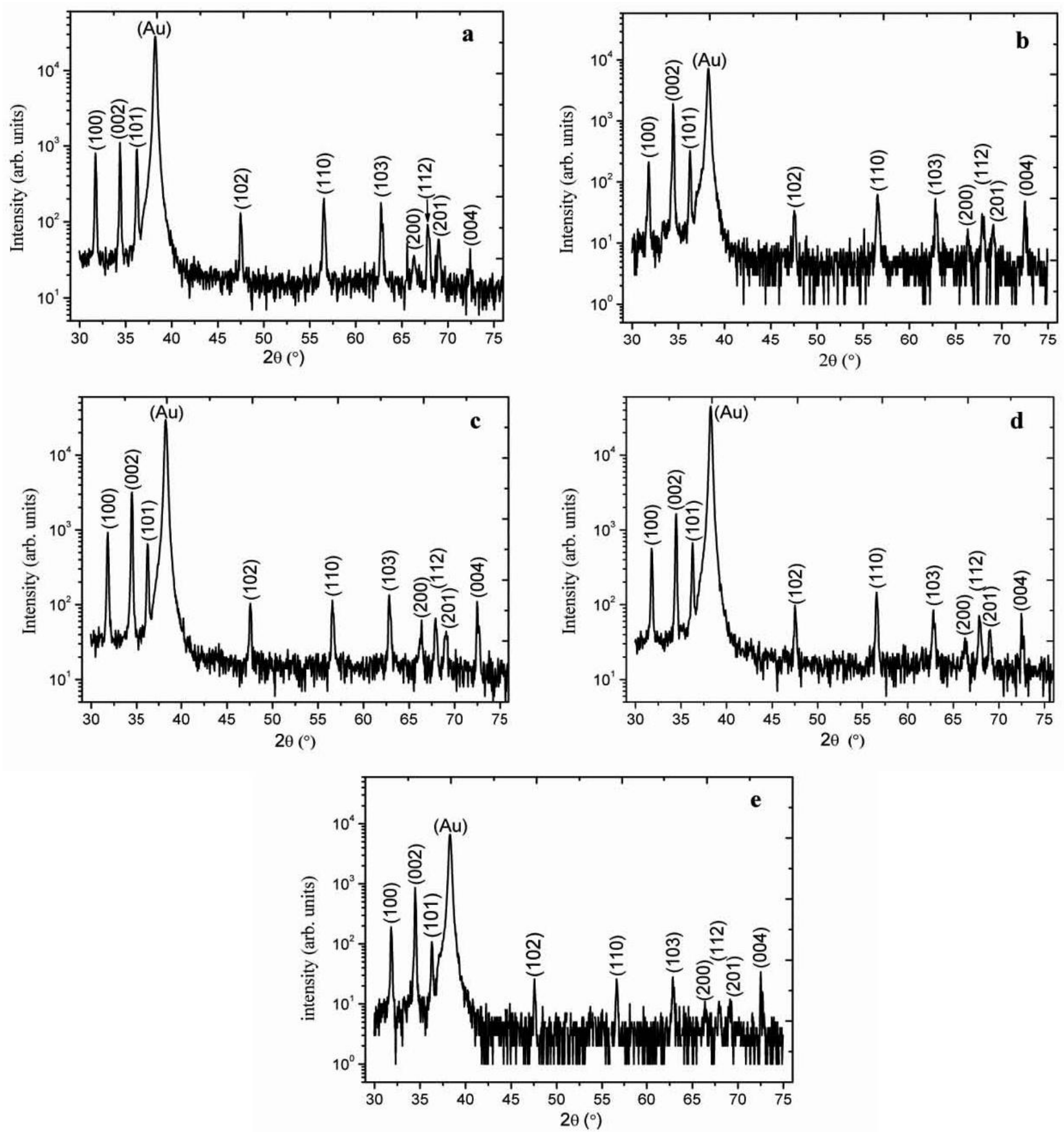
Figure 4. The XRD pattern of $\mathrm{ZnO}$ nanorods growth with seed solutions containing $3.5 \mathrm{mg} / \mathrm{mL}$ of cellulose concentration with different concentrations of $\mathrm{ZnO}$ nanoparticle: (a) 1.0 ; (b) 3.5 ; and (c) $7.5 \mathrm{mg} / \mathrm{mL}$.
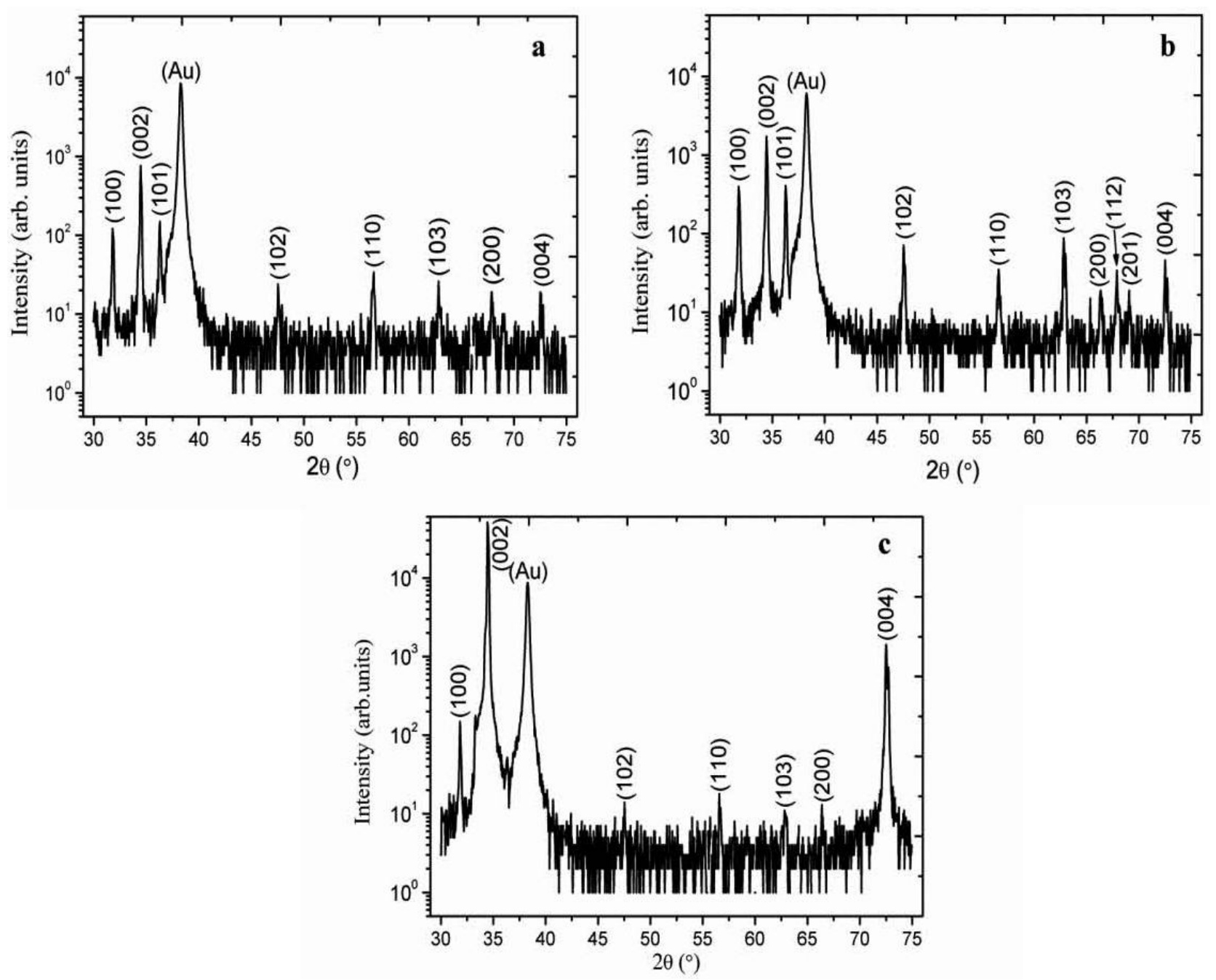

Figure 5. The FESEM image of $\mathrm{ZnO}$ nanorods grown with only $\mathrm{ZnO}$ nanoparticles seed solution.

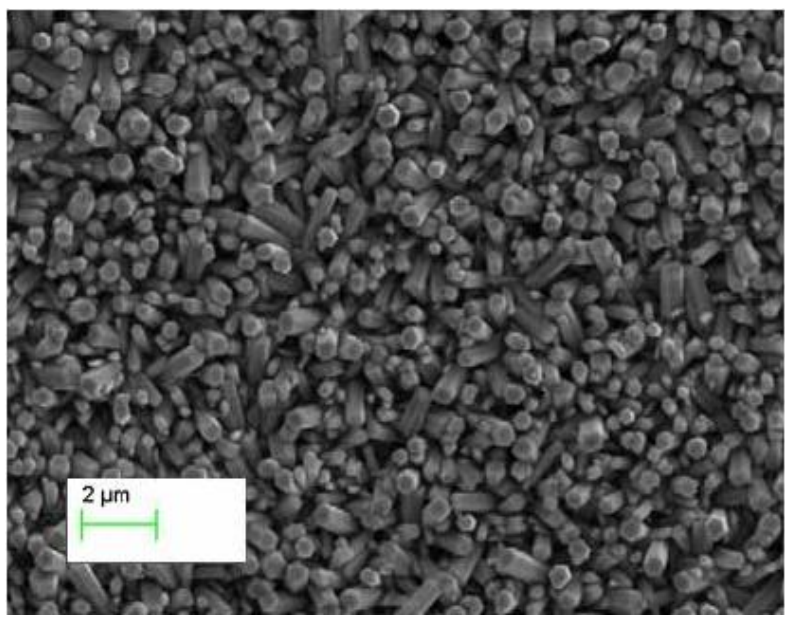


Figure 6. The FESEM images of $\mathrm{ZnO}$ nanorods with seed solutions containing $3.5 \mathrm{mg} / \mathrm{mL}$ of starch concentration and (a) 0 ; (b) 0.5 ; (c) 1.0 ; (d) 1.5 ; (e) 2.0 ; (f) $2.5 \mathrm{mg} / \mathrm{mL}$ of $\mathrm{ZnO}$ nanoparticles concentration; and (g) cross section image of $\mathrm{ZnO}$ nanorods growth with $\mathrm{f}$ condition.

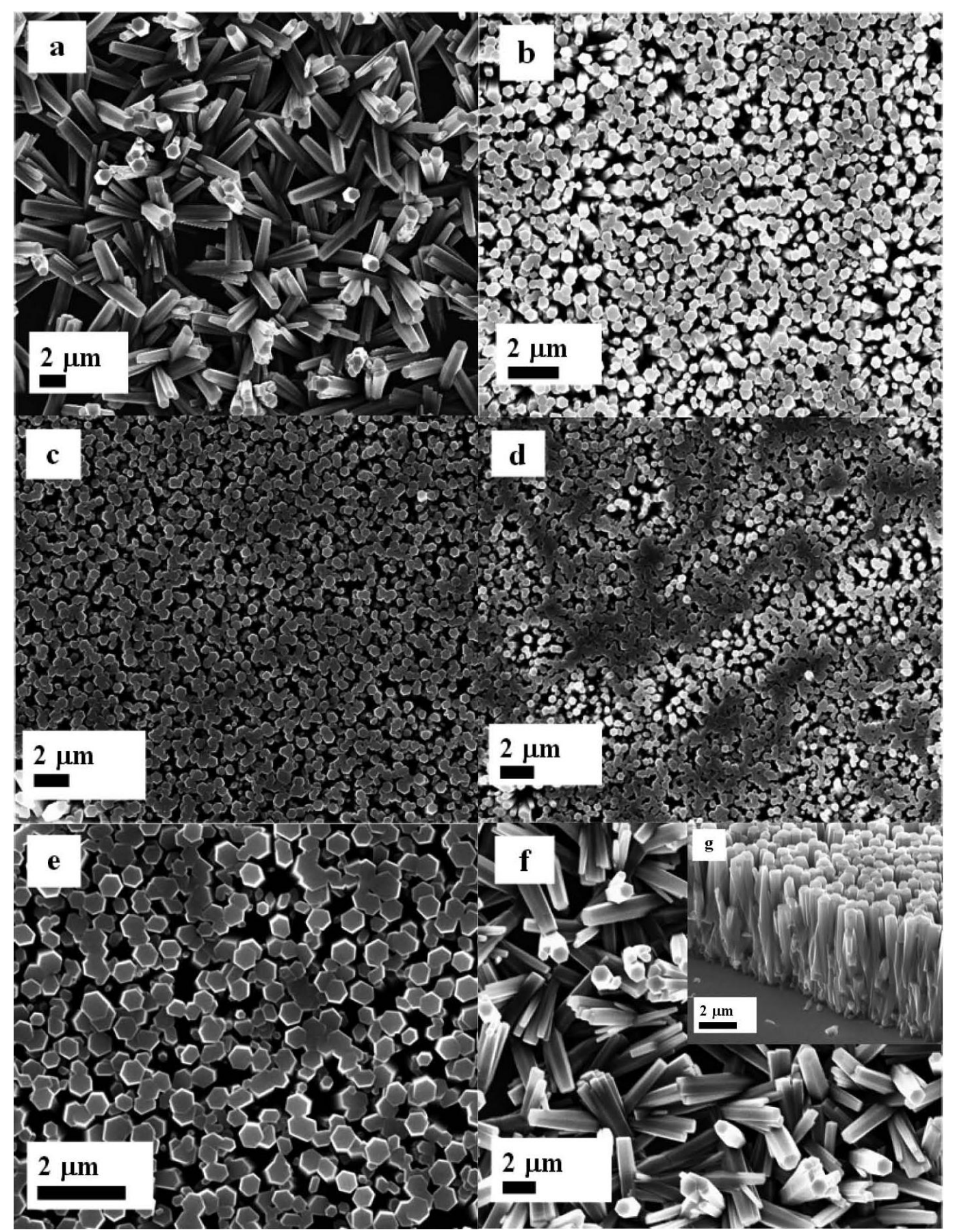

Figure $7 \mathrm{a}-\mathrm{e}$ shows top view FESEM images of $\mathrm{ZnO}$ nanorods fabricated with a cellulose biopolymer seed layer. It can be seen from Figure 7a that omitting the $\mathrm{ZnO}$ nanoparticles in the seed layer results in nanorods that grow with larger rod to rod separations and a random alignment. When $1.0 \mathrm{mg} / \mathrm{mL}$ of $\mathrm{ZnO}$ nanoparticles were introduced in the cellulose solution, the nanorods started to grow in random directions, as shown in Figure 7b. However, for seed layer containing 3.5 and $7.5 \mathrm{mg} / \mathrm{mL}$ of $\mathrm{ZnO}$ nanoparticles in cellulose solution, the $\mathrm{ZnO}$ nanorods are grown highly ordered and 
dense on the substrate, as shown in Figure 7c,d. Cellulose, being a member of the starch family, shows similar effects on the alignment of the $\mathrm{ZnO}$ nanorods as starch does. The FESEM study demonstrates that $\mathrm{ZnO}$ nanorods synthesized by a seed layer of $\mathrm{ZnO}$ nanoparticles with biopolymers exhibit a hexagonal crystal structure and are oriented along the $c$-axis of the substrate, which is consistent with the XRD results. The diameters of the nanorods, grown by a combination of organic and inorganic materials in the seed layer, are in the range of $100 \mathrm{~nm}$ to $200 \mathrm{~nm}$. In other words, the deposition of biocomposite seed layer of $\mathrm{ZnO}$ nanoparticles not only assists to control the yield of nanorods, diameter, and their uniform distribution, but also enhances the overall alignment orientation of $\mathrm{ZnO}$ nanorods. The EDX technique was used for the study of composition of $\mathrm{ZnO}$ nanorods and the obtained results indicate that the prepared sample is only composed of $\mathrm{Zn}$ and $\mathrm{O}$ atoms as shown in Figure 8.

Figure 7. The FESEM images of $\mathrm{ZnO}$ nanorods with seed solutions containing $3.5 \mathrm{mg} / \mathrm{mL}$ of cellulose concentration with difference amount: (a) 0 ; (b) 1.0 ; (c) 3.5 ; (d) $7.5 \mathrm{mg} / \mathrm{mL}$ of $\mathrm{ZnO}$ nanoparticles concentration; and (e) cross section image of $\mathrm{ZnO}$ nanorods growth with d condition.

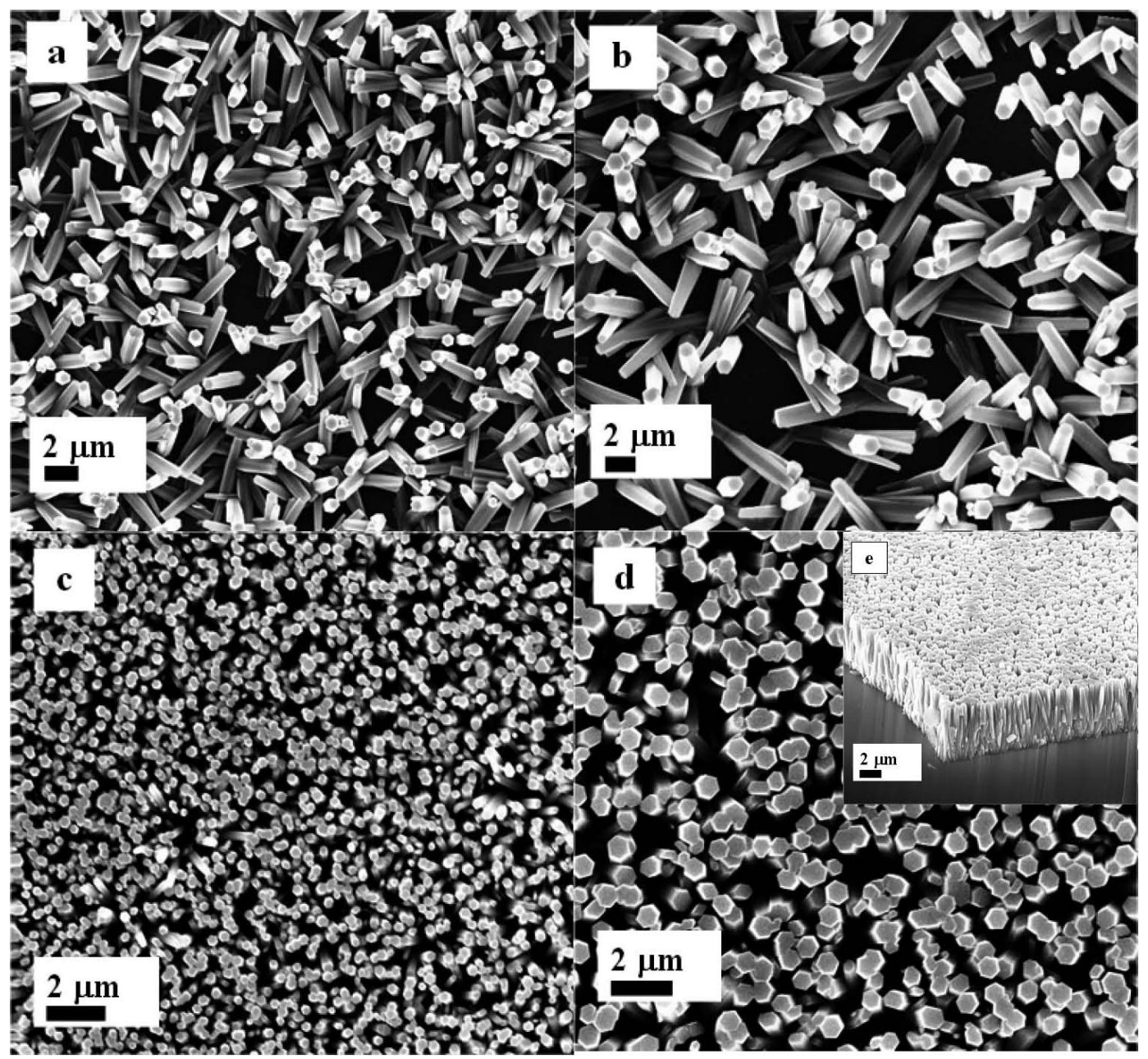

Photoluminescence (PL) is the efficient tool to study the optical, electronic and structural characteristics of different materials. PL study was carried out for the investigation of defect states and crystal quality of fabricated $\mathrm{ZnO}$ nanorods using biocomposite seed layer of $\mathrm{ZnO}$ nanoparticles. 
A room temperature PL spectroscopy study has been carried out in order to get insight into the optical properties of the $\mathrm{ZnO}$ nanorods grown on the biocomposite seed layer containing $\mathrm{ZnO}$ nanoparticles. The PL emission of a sample containing $\mathrm{ZnO}$ nanorods grown on a seed layer consisting of $2.0 \mathrm{mg} / \mathrm{mL}$ of $\mathrm{ZnO}$ nanoparticles in $3.5 \mathrm{mg} / \mathrm{mL}$ of starch is shown by the spectrum in Figure 9a. Figure $9 \mathrm{~b}$ shows the PL emission from a sample containing $\mathrm{ZnO}$ nanorods grown on a seed layer consisting of $7.5 \mathrm{mg} / \mathrm{mL}$ of $\mathrm{ZnO}$ nanoparticles in $3.5 \mathrm{mg} / \mathrm{mL}$ of cellulose. In both PL spectra, three different emission peaks are observed.

Figure 8. The EDX of $\mathrm{ZnO}$ nanorods.

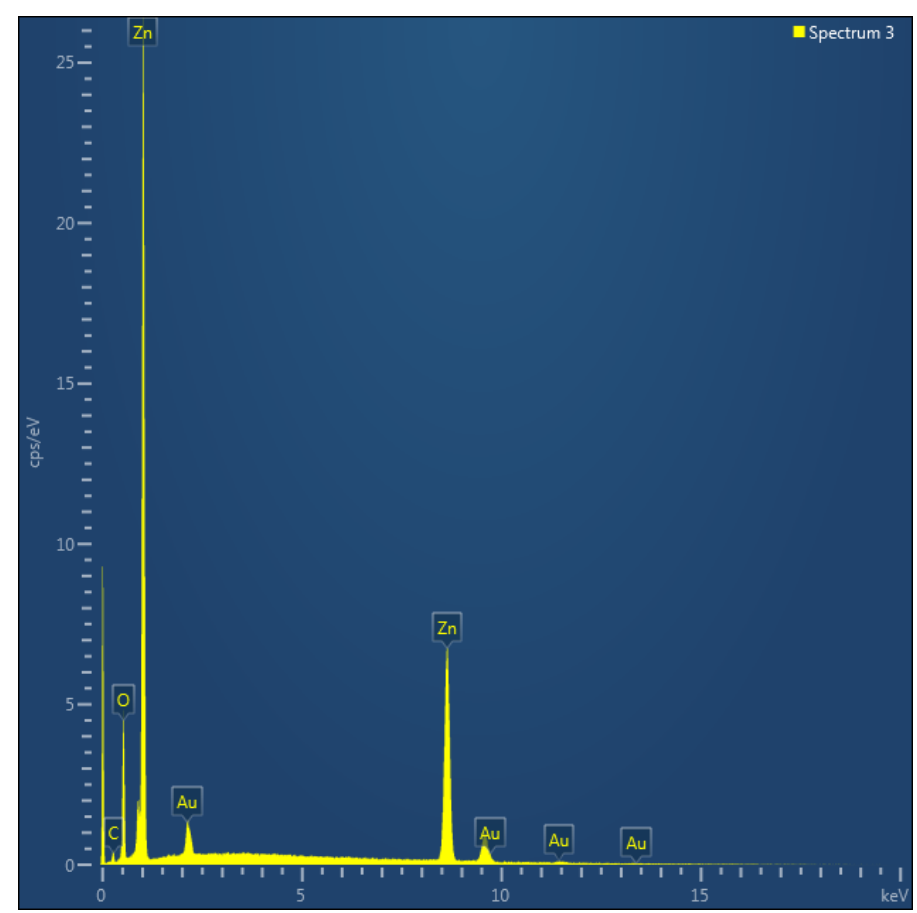

Figure 9. The room temperature PL spectra of $\mathrm{ZnO}$ nanorods grown with difference seed layer solution consisting of (a) $2.0 \mathrm{mg} / \mathrm{mL}$ of $\mathrm{ZnO}$ nanoparticles in $3.5 \mathrm{mg} / \mathrm{mL}$ of starch concentration; (b) $7.5 \mathrm{mg} / \mathrm{mL}$ of $\mathrm{ZnO}$ nanoparticles in $3.5 \mathrm{mg} / \mathrm{mL}$ of cellulose concentration.
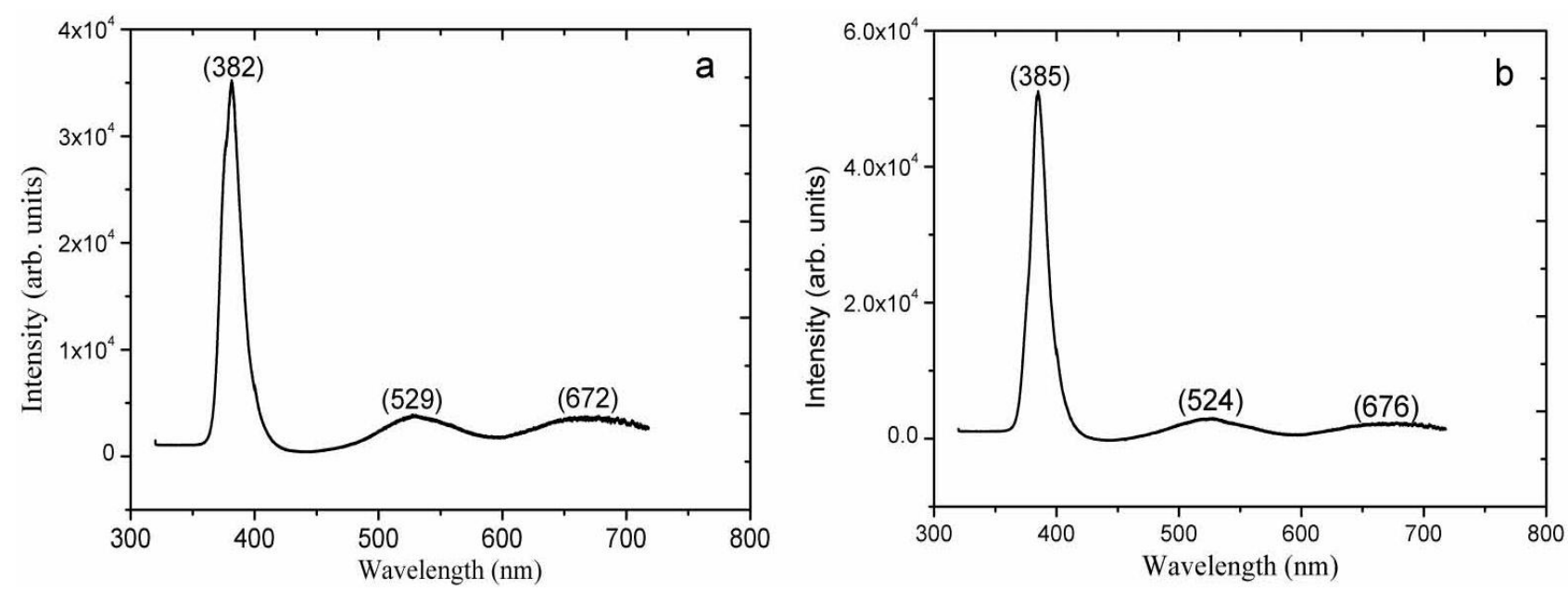
The UV emission is the dominating contribution in both spectra, and has a maximum at $382 \mathrm{~nm}$ and $385 \mathrm{~nm}(3.24 \mathrm{eV}$ and $3.22 \mathrm{eV})$, for the $\mathrm{ZnO}$ sample grown on a starch seed layer and a cellulose seed layer, respectively. These spectral peaks originate from near band edge (NBE) emission, such as recombination of free excitons. In addition to the slight red shift of the NBE emission from the $\mathrm{ZnO}$ sample utilizing a cellulose seed layer, the PL intensity is also a bit higher than when starch was used as a seed layer which might be due to possible more defect states in the sample grown with the seed solution of cellulose. The two other peaks found in the PL spectra are very broad and appear at $530 \mathrm{~nm}$ and $670 \mathrm{~nm}(2.3 \mathrm{eV}$ and $1.8 \mathrm{eV})$. They are attributed to defects in the material.

Green PL emission from $\mathrm{ZnO}$ is quite common, and has been observed from $\mathrm{ZnO}$ nanorods prepared by low temperature aqueous chemical growth [34,35], vapor-liquid-solid growth [36], CVD [37,38] and the electrochemical growth techniques $[39,40]$. The green emission is attributed to the recombination of electrons at oxygen vacancies with holes in the valence band [40]. The orange/red emission from $\mathrm{ZnO}$ is less well understood. However, oxygen interstitials in the $\mathrm{ZnO}$ crystal are possible contributors to this emission [41-44]. The PL results of the ZnO nanorods sample grown on a starch and cellulose seed layer, respectively, both show defects related emission that is much weaker than the NBE emission, indicating a low concentration of defects, such as oxygen vacancies. Moreover, PL study has described good crystal quality with less defects states in $\mathrm{ZnO}$ nanorods using the biocomposite seed layer of $\mathrm{ZnO}$ nanoparticles.

\section{Experimental Section}

\subsection{Preparation of ZnO Nanoparticles Seed Solution in Starch and Cellulose Biopolymers}

The seed solution of $\mathrm{ZnO}$ nanoparticles without using biopolymers was prepared in $1 \%$ acetic acid solution with concentration of $3.5 \mathrm{mg} / \mathrm{mL}$ in order to study the role of starch and cellulose on the alignment and orientation of $\mathrm{ZnO}$ nanorods. The seed solution of $\mathrm{ZnO}$ nanoparticles in starch and cellulose was prepared in a $1 \%$ acetic acid solution in an ultrasonic bath for $15 \mathrm{~min}$. The average size of the $\mathrm{ZnO}$ particles used as the seed was about $12.2 \mathrm{~nm}$. Different quantities of $\mathrm{ZnO}$ nanoparticles, including $0.5,1.0,1.5,2.0$, and $2.5 \mathrm{mg} / \mathrm{mL}$ were dissolved in the mixture of $10 \mathrm{~mL}$ of $1 \%$ acetic acid and $3.5 \mathrm{mg} / \mathrm{mL}$ of starch. Likewise, seed solution containing $3.5 \mathrm{mg} / \mathrm{mL}$ of cellulose and $0,1.0,3.5$ and $7.5 \mathrm{mg} / \mathrm{mL}$ of $\mathrm{ZnO}$ nanoparticles was prepared in $10 \mathrm{~mL}$ of $1 \%$ acetic acid solution. Different concentrations of $\mathrm{ZnO}$ nanoparticles were used for monitoring of the effect of nanoparticles on the alignment of nanorods. The seed solutions of starch and cellulose were individually prepared and separately used as seed layer for the fabrication of well aligned $\mathrm{ZnO}$ nanorods on the gold-coated glass substrate.

\subsection{Synthesis of ZnO Nanorods on Gold-Coated Glass Substrates}

Prior to growth of $\mathrm{ZnO}$ nanorods, glass substrates were coated with $100 \mathrm{~nm}$ thickness of gold. The gold coating process began by cleaning the glass substrates with isopropanol in an ultrasonic bath for $20 \mathrm{~min}$. These were then washed with the deionized water and dried in air. Then, the cleaned glass substrates were affixed in the deposition chamber of the evaporator, Satis (725). After achieving vacuum inside the chamber, an adhesive layer of titanium, with a thickness of $20 \mathrm{~nm}$, was deposited on 
the glass substrate, followed by the deposition of $100 \mathrm{~nm}$ thickness of gold. After gold layer deposition, the substrates were cleaned with the deionized water and dried in a nitrogen gas flow. The substrates were then spin coated with the composite seed solution of $\mathrm{ZnO}$ nanoparticles and starch two to three times at 3000 r.p.m. for 30 s. Similarly, the gold layer coated substrates were also spin coated with the composite seed solution of $\mathrm{ZnO}$ nanoparticles and cellulose. After the seed layer deposition, the substrates were annealed at $120{ }^{\circ} \mathrm{C}$ for $20 \mathrm{~min}$. An equimolar solution of $75 \mathrm{mM}$ of zinc nitrate hexahydrate and hexamethylenetetramine (HMT) was prepared in the deionized water and the annealed substrates were fixed in a Teflon sample holder. These were then vertically dipped in the precursor solution and covered with aluminum foil. The growth solution was kept in a preheated oven for four to seven hours at $96{ }^{\circ} \mathrm{C}$. After the completion of growth period, the $\mathrm{ZnO}$ nanostructures on gold-coated substrates were washed with the deionized water in order to remove the solid $\mathrm{ZnO}$ powder from the surface of the nanostructures, and then dried in air at room temperature.

The crystal structure of $\mathrm{ZnO}$ nanoparticles and nanorods was studied by scans $(0.1 / \mathrm{s})$ Phillips PW 1729 powder diffractometer using the $\mathrm{CuK} \alpha$ radiation $(\lambda=1.5418 \AA)$. An atomic force microscope (AFM, Dimension 3100) was used for the morphological study of biocomposite seed layer of $\mathrm{ZnO}$ nanoparticles. The field emission scanning electron microscopy (FESEM) that was performed using LEO 1550 Gemini, field emission gun was operated at $20 \mathrm{kV}$ for the morphological study of $\mathrm{ZnO}$ nanorods and energy-dispersive X-ray (EDX). In the photoluminescence technique a third harmonics $(\lambda \mathrm{e}=266 \mathrm{~nm})$ from a Coherent Ti: sapphire laser was used and the detection was performed with Hamamatsu CCD camera. For the dispersion of PL signal a single monochromator of $1 \mathrm{~m}$ focal length (model Brucker Optics Chromex 25) is combined with a diffraction grating of 150 lines $/ \mathrm{mm}$.

\section{Conclusions}

In this work, well aligned $\mathrm{ZnO}$ nanorods were synthesized by hydrothermal growth technique on the gold-coated glass substrates using the biocomposite seed layer of $\mathrm{ZnO}$ nanoparticles in starch and cellulose, respectively. The biocomposite seed layer of $\mathrm{ZnO}$ nanoparticles has influence on the alignment and diameter of $\mathrm{ZnO}$ nanorods. The morphological study of the biocomposite seed layer of $\mathrm{ZnO}$ nanoparticles was studied by AFM and the nanoparticles are distributed uniform and well adhered to the surface of gold-coated glass substrate. The $\mathrm{ZnO}$ nanorods were characterized by XRD technique, FESEM imaging, and PL spectroscopy and the obtained results show that the nanorods are uniformly distributed with a high density, having well-ordered alignment along the $c$-axis of the substrate, and exhibited good crystal quality. The present approach for the fabrication of $\mathrm{ZnO}$ nanorods can be used for the development of improved performance optoelectronic devices such as white LEDs where the rod alignment has a significant effect on the performance of the device.

\section{Acknowledgments}

We are thankful to Deanship of Scientific Research at King Saud University through the research group project number: RGP-VPP-023, who financially supported this research work and Fredrik Karlsson researcher at IFM department of physics, chemistry and biology IFM Linköping University Sweden for helping the PL measurement 


\section{Conflicts of Interest}

The authors declare no conflict of interest.

\section{References}

1. Huang, M.H.; Mao, S.; Feick, H.; Yan, H.; Wu, Y.; Kind, H.; Weber, E.; Russo, R.; Yang, P. Room-temperature ultraviolet nanowire nanolasers. Science 2001, 292, 1897-1899.

2. Tu, Z.C.; Hu, X. Elasticity and piezoelectricity of zinc oxide crystals, single layers and possible single-walled nanotubes. Phys. Rev. B 2006, 74, 035434:1-035434:6.

3. Song, J.H.; Zhou, J.; Wang, Z.L. Piezoelectric and semiconducting coupled power generating process of a single $\mathrm{ZnO}$ Belt/Wire. A technology for harvesting electricity from the environment. Nano Lett. 2006, 6, 1656-1662.

4. Wang, X.D.; Summers, C.J.; Wang, Z.L. Large-scale hexagonal-patterned growth of aligned ZnO nanorods for nano-optoelectronics and nanosensor arrays. Nano Lett. 2004, 4, 423-426.

5. Wang, C.H.; Chu, X.F.; Wu, M.W. Detection of $\mathrm{H}_{2} \mathrm{~S}$ down to ppb levels at room temperature using sensors based on $\mathrm{ZnO}$ nanorods. Sens. Actuators B Chem. 2006, 113, 320-323.

6. Baxter, J.B.; Walker, A.M.; Ommering, K.V.; Aydil, E.S. Synthesis and characterization of ZnO nanowires and their integration into dye-sensitized solar cells. Nanotechnology 2006, 17, S304-S312.

7. Liu, T.Y.; Liao, H.C.; Lin, C.C.; Hu, S.H.; Chen, S.Y. Biofunctional ZnO nanorod arrays grown on flexible substrates. Langmuir 2006, 22, 5804-5809.

8. Cao, B.Q.; Lorenz, M.; Rahm, A.; Wenckstern, H.; Czekalla, C.; Lenzner, J.; Benndorf, G.; Grundmann, M. Phosphorus acceptor doped $\mathrm{ZnO}$ nanowires prepared by pulsed-laser deposition. Nanotechnology 2007, 18, 455707:1-455707:45.

9. Shen, G.; Bando, Y.; Lee, C.J. Synthesis and evolution of novel hollow $\mathrm{ZnO}$ urchins by a simple thermal evaporation process. J. Phys. Chem. B 2005, 109, 10578-10583.

10. Liao, L.; Liu, D.H.; Li, J.C.; Liu, C.; Fu, Q.; Ye, M.S. Synthesis and raman analysis of 1D-ZnO nanostructure via vapor phase growth. Appl. Surf. Sci. 2005, 240, 175-179.

11. Heo, Y.W.; Varadarajan, V.; Kaufman, M.; Kim, K.; Norton, D.P.; Ren, F.; Fleming, P.H. Site-specific growth of Zno nanorods using catalysis-driven molecular-beam epitaxy. Appl. Phys. Lett. 2002, 81, 3046-3048.

12. Liu, X.; Wu, X.; Cao, H.; Chang, R.P.H. Growth mechanism and properties of ZnO nanorods synthesized by plasma-enhanced chemical vapor deposition. J. Appl. Phys. 2004, 95, 3141-3147.

13. Khranovskyy, V.; Tsiaoussis, I.; Hultman, L.; Yakimova, R. Selective homoepitaxial growth and luminescent properties of $\mathrm{ZnO}$ nanopillars. Nanotechnology 2011, 22, 185603:1-185603:18.

14. Park, W.I.; Kim, D.H.; Jung, S.W.; Brown, N.M.D. Control and mass selection of $\mathrm{C}_{n} \mathrm{H}_{m}{ }^{+}$ fragments in an inductively coupled pulsed plasma. Appl. Phys. Lett. 2002, 80, 22-24.

15. Kim, S.; Jeong, M.C.; Oh, B.Y.; Lee, W.; Myoung, J.M. Fabrication of $\mathrm{Zn} / \mathrm{ZnO}$ nanocables through thermal oxidation of $\mathrm{Zn}$ nanowires grown by RF magnetron sputtering. J. Cryst. Growth 2006, 290, 485-489.

16. Anthony, S.P.; Lee, J.I.; Kim, J.K. Tuning optical band gap of vertically aligned $\mathrm{ZnO}$ nanowire arrays grown by homoepitaxial electrodeposition. Appl. Phys. Lett. 2007, 90, 103107:1-103107:3. 
17. Guo, M.; Diao, P.; Wang, X.; Han, J.S.; Ma, H.; Zhao, X.H.; Zhao, X.H. A novel route to synthesize cubic $\mathrm{ZrW}_{2-} \mathrm{Mo}_{x} \mathrm{O}_{8}(x=0-1.3)$ solid solutions and their negative thermal expansion properties. J. Solid State Chem. 2005, 178, 3166-3171.

18. Li, C.; Fang, G.; Su, F.; Li, G.; Wu, X.; Zhao, X. Synthesis and photoluminescence properties of vertically aligned $\mathrm{ZnO}$ nanorod-nanowall junction arrays on a $\mathrm{ZnO}$-coated silicon substrate. Nanotechnology 2006, 17, 3740:1-3740:15.

19. Umar, A.; Karunagaran, B.; Suh, E.K.; Hahn, Y.B. Structural and optical properties of single-crystalline $\mathrm{ZnO}$ nanorods grown on silicon by thermal evaporation. Nanotechnology 2006, 17, 4072:1-4072:16.

20. Kumar, P.S.; Raj, A.D.; Mangalaraj, D.; Nataraj, D. Growth and characterization of $\mathrm{ZnO}$ nanostructured thin films by a two-step chemical method. Appl. Surf. Sci. 2008, 255, 2382-2387.

21. Breedona, M.; Rahmani, M.B.; Keshmir, S.H.; Wlodarskia, W.; Zadeh, K.K. Aqueous synthesis of interconnected $\mathrm{ZnO}$ nanowires using spray pyrolysis deposited seed layers. Mater. Lett. 2010, 64, 291-294.

22. Zoolfakar, A.S.; Kadir, R.A.; Rani, R.A.; Balendhran, S.; Liu, X.; Kats, E.; Bhargava, S.K.; Bhaskaran, M.; Sriram, S.; Zhuiykov, S.; O’Mullane, A.P.; Zadeh, K.K. Engineering electrodeposited $\mathrm{ZnO}$ films and their memristive switching performance. Phys. Chem. Chem. Phys. 2013, 15, 10376-10384.

23. Zoolfakar, A.S.; Rani, R.A.; Morfa, A.J.; Balendhran, S.; O’Mullane, A.P.; Zhuiykov, S.; Zadeh, K.K. Enhancing the current density of electrodeposited $\mathrm{ZnO}-\mathrm{Cu}_{2} \mathrm{O}$ solar cells by engineering their heterointerfaces. J. Mater. Chem. 2012, 22, 21767-21775.

24. Mann, S. The chemistry of form. Angew. Chem. Int. Ed. 2000, 39, 3392-3406.

25. Murphy, W.L.; Mooney, D.J. Bioinspired growth of crystalline carbonate apatite on biodegradable polymer substrata. J. Am. Chem. Soc. 2002, 124, 1910-1917.

26. Landfester, K. The generation of nanoparticles in miniemulsions. Adv. Mater. 2001, 13, 765-768.

27. Aizenberg, J.; Black, A.J.; Whitesides, G.M. Control of crystal nucleation by patterned self-assembled monolayers. Nature 1999, 398, 495-498.

28. Braun, E.; Eichen, Y.; Sivan, U.; Ben-Yoseph, G. DNA-templated assembly and electrode attachment of a conducting silver wire. Nature 1998, 391, 775-778.

29. Storhoff, J.J.; Mirken, C.A. Programmed materials synthesis with DNA. Chem. Rev.1999, 99, 1849-1862.

30. Ogasawara, W.; Shenton, W.; Davis, S.A.; Mann, S. Template mineralization of ordered macroporous chitin-silica composites using cuttlebone-derived organic matrix. Chem. Mater. 2000, 12, 2835-2837.

31. Shin, Y.; Liu, J.; Chang, J.H.; Nie, Z.; Exarhos, G.J.; Hierarchically ordered ceramics through surfactant-templated sol-gel mineralization of biological cellular structures. Adv. Mater. 2001, 13, $728-732$.

32. Thomas, D.J.; Atwell, W.A. Starch Structure in Starches Practical Guide for the Food Industry; Eagan Press: St. Paul, MN, USA, 1999.

33. Mishra, S.K.; Srivatava, R.K.; Prakash, S.G.; Yadav, R.S.; Panday, A.C. Photoluminescence and photoconductive characteristics of hydrothermally synthesized $\mathrm{ZnO}$ nanoparticles, Opto-Electron. Rev. 2000, 18, 467-473. 
34. Zhang, J.; Sun, L.D.; Lin, Y.J.; Su, H.; Liao, C.; Yan, C. Control of ZnO morphology via a simple solution route. Chem. Mater. 2002, 14, 4172-4177.

35. Zhang, J.; Sun, L.D.; Pan, H.Y.; Liao, C.; Yan, C. ZnO nanowires fabricated by a convenient route. New J. Chem. 2002, 26, 33-34.

36. Huang, M.H.; Wu, Y.; Feick, H.; Tran, N.; Weber, E.; Yang, P. Catalytic growth of zinc oxide nanowires by vapor transport. Adv. Mater. 2001, 13, 113-116.

37. $\mathrm{Wu}$, J.J.; Liu, S.C. Low-temperature growth of well-aligned $\mathrm{ZnO}$ nanorods by chemical vapor deposition. Adv. Mater. 2002, 14, 215-218.

38. Wu, J.J.; Liu, S.C. Catalyst-free growth and characterization of $\mathrm{ZnO}$ nanorods. J. Phys. Chem. B 2002, 106, 9546-9551.

39. Li, Y.; Meng, G.W.; Zhang, L.D.; Phillipp, F. Ordered semiconductor ZnO nanowire arrays and their photoluminescence properties. Appl. Phys. Lett. 2000, 76, 2011-2013.

40. Wang, Y.C.; Leu, I.C.; Hon, M.H. Effect of colloid characteristics on the fabrication of $\mathrm{ZnO}$ nanowire arrays by electrophoretic deposition. J. Mater. Chem. 2002, 12, 2439-2444.

41. Greene, L.E.; Law, M.; Goldberger, J.; Kim, F.; Johnson, J.C.; Zhang, Y.; Saykally, R.J.; Yang, P. Low-temperature wafer-scale production of $\mathrm{ZnO}$ nanowire arrays. Angew. Chem. Int. Ed. 2003, 42, 3031-3034.

42. Liu, M.; Kitai, A.H.; Mascher, P. Point defects and luminescence centres in zinc oxide and zinc oxide doped with manganese. J. Lumin. 1992, 54, 35-42.

43. Wu, X.L.; Siu, G.G.; Fu, C.L.; Ong, H.C. Photoluminescence and cathodoluminescence studies of stoichiometric and oxygen-deficient $\mathrm{ZnO}$ films. Appl. Phys. Lett. 2001, 78, 2285-2287.

44. Studenikin, S.A.; Golego, N.; Cocivera, M. Fabrication of green and orange photoluminescent, undoped $\mathrm{ZnO}$ films using spray pyrolysis. J. Appl. Phys. 1998, 84, 2287-2294.

(C) 2013 by the authors; licensee MDPI, Basel, Switzerland. This article is an open access article distributed under the terms and conditions of the Creative Commons Attribution license (http://creativecommons.org/licenses/by/3.0/). 